\title{
Perancangan E-Kuisioner menggunakan CodeIgniter dan React-Js sebagai Tools Pendukung Penelitian
}

\author{
Ismail ${ }^{1}$, Fauzan Putraga Al Bahri ${ }^{2}$ \\ 1,2Program Studi Manajemen Informatika \\ ${ }^{1,2}$ AMIK Indonesia \\ JL. Teuku Nyak Arif, Simpang Krueng Raya, Jeulingke, Syiah Kuala, Banda Aceh, Provinsi \\ Aceh, (0651) 52043 \\ ismail@amikindonesia.ac.id
}

\begin{abstract}
The development of questionnaires that can capture usability problems in each case is expected to be more effective and efficient. At present, the use of e-questionnaires has evolved with the use of technologies such as the emergence of monkey surveys, type forms, google forms, Zoho surveys, and gizmo surveys that can be used to facilitate the work of creating, distributing and retrieving survey feedback online. This research tries to build an e-questionnaire model using Codeigniter and react-js which can be used as an alternative while prioritizing the appearance of end-users by adopting the Google form service but having features by being able to add questions in the form of multimedia and also being able to disseminate information on survey results with the concept of sharing datasets to various digital online sources. The methodology used in the research to be carried out is the DSRM (Design Science Research Method) method and at the research, the stage consists of; problem identification, defining objects and solutions, design and development, implementation, evaluation, and conclusion. This research resulted in an e-questionnaire application that can be used as an alternative while prioritizing the appearance of end-users by adopting the Google form service but has features that can add questions in the form of multimedia and can also disseminate survey results with the concept of sharing datasets to various digital sources. online with the use of the Codelnigter and React-Js framework can improve effective appearance while maintaining system security. It is hoped that the e-questionnaire can increase the distribution of research data in the form of electronic datasets and can be fully used as a reference for researchers in Indonesia, especially AMIK Indonesia.
\end{abstract}

Keywords: maximum 5 keywords from paper

\begin{abstract}
Abstrak
Perkembangan kuesioner yang dapat menangkap masalah usabilitas pada setiap kasus diharapkan agar dapat lebih efektif dan efisien. Saat ini penggunaan e-kuisioner telah berkembang dengan pemanfaatan teknologi seperti munculnya survey monkey, typeform, google forms, zoho survey, dan survey gizmo bisa digunakan untuk mempermudah pekerjaan dalam membuat, menyebarkan dan mendapatkan kembali feedback survei secara online. Penelitian ini mencoba untuk membangun model e-kuisioner menggunakan Codeigniter dan react-js yang dapat digunakan sebagai alternatif dengan tetap mengutamakan tampilan bagi end user dengan mengadopsi layanan google form tetapi memiliki fitur dengan dapat menambah pertanyaan dalam bentuk multimedia dan juga dapat menyebarkan informasi hasil survei dengan konsep sharing dataset ke berbagai sumber digitalonline. Metodelogi yang digunakan dalam penelitian yang akan dilaksanakan adalah metode DSRM (Design Science Research Method) serta pada tahap penelitian terdiri dari; identifikasi masalah, mendefinisikan objek dan solusi, desain dan pengembangan, implementasi, evaluasi dan pengambilan kesimpulan. Penelitian ini menghasilkan sebuah aplikasi e-kuisioner yang dapat digunakan sebagai alternatif dengan tetap mengutamakan tampilan bagi end user dengan mengadopsi layanan google form tetapi memiliki fitur dengan dapat menambah pertanyaan
\end{abstract}

Perancangan E-Kuisioner menggunakan CodeIgniter dan React-Js ... (Ismail) | 337 
dalam bentuk multimedia dan juga dapat menyebarkan informasi hasil survei dengan konsep sharing dataset ke berbagai sumber digital online dengan penggunaan framework Codelnigter dan React-Js dapat meningkatkan tampilan yang efektif dengan tetap mengutamakan keamanan sistem. Diharapkan dengan adanya e-kuisioner dapat meningkatkan penyebaran data penelitian dalam bentuk dataset secara elektronik serta sepenuhnya dapat digunakan sebagai referensi bagi peneliti-peneliti di Indonesia khususnya AMIK Indonesia.

Kata kunci: E-Questionnaire, Codeigniter, React-Js, AMIK Indonesia.

\section{PENDAHULUAN}

Kuisioner merupakan suatu proses terhadap jumlah pertanyaan tertulis yang digunakan untuk memperoleh informasi dari responden sebagai upaya pengambilan informasi dalam arti laporan tentang pribadinya atau hal-hal yang ia ketahui tujuan pokok dari kuisioner [1]. Perkembangan kuesioner yang dapat menangkap masalah usabilitas pada setiap kasus diharapkan agar dapat lebih efektif dan efisien. Saat ini penggunaan e-kuisioner telah berkembang dengan pemanfaatan teknologi seperti munculnya survey monkey, typeform, google forms, zoho survey, dan survey gizmo bisa digunakan untuk mempermudah pekerjaan dalam membuat, menyebarkan dan mendapatkan kembali feedback survei secara online [2]. Dari hasil survey google trends menyebutkan bahwa google forms memiliki angka peminat tertinggi sebesar 48\%, diikuti survey monkey sebesar 20\%, selanjutnya typeform, zoho survey, dan survey gizmo rata-rata $10 \%$ dalam kurun waktu 5 tahun. Maka e-kuisioner merupakan dianggap penting dalam pengumpulan dan penyebaran data secara online dimana tools tersebut memiliki kelebihan seperti logika survei, data ekspor, custom logo, dan membuat pertanyaan tanpa batas, terdapat beberapa tools kuisioner online yang digunakan seperti survey monkey [3], typeform [4], google forms [5], zoho survey [6], dan survey gizmo [7].

Beberapa peneliti telah melakukan penelitian terkait e-kuisioner, seperti yang dilakukan Dhanavandan (2016), penelitian ini membahas langkah demi langkah cara membuat alat survei menggunakan Google Form, Selain itu juga membahas tentang berbagai alat yang digunakan untuk penelitian di perpustakaan dan ilmu informasi [8]. Selanjutnya, Mane dan Kumbhar (2015) melakukan penelitian tentang tools online bagi peneliti agar meningkatkan kualitas penelitian dengan cara efektif, hasil penelitian ini menyatakan bahwa penggunaan alat penelitian online dapat membantu peneliti dalam semua fase penelitian akan menjadi layanan nilai tambah dari perpustakaan [9]. Pasek dan Krosnick (2010) menyebutkan bahwa penggunaan kuisioner online dengan menerapkan praktik yang terbaik dalam desain kuesioner akan menghasilkan data yang lebih akurat dan temuan substantif yang lebih akurat tentang sifat dan asal-usul perilaku politik massa [10]. Dari hasil penelitian terkait maka masih dalam implementasi penggunaan serta manfaat kuisioner online, keterkaitan secara substantive belum ditemukan terhadap subjek penelitian secara detail. Diharapkan penelitian ini dapat menunjukkan kebaruan dari system baru dengan 
menerapkan antar muka dan fungsional lebih substantive, aktraktir dan efektif.

Penggunaan Codelnigter memudahkan pengembangan pemrograman aplikasi web [11], serta dengan dukungan React-Js dapat memudahkan pengembangan disisi server menjadi lebih baik [12], dengan penggabungan keduanya dapat menerapkan sisi keamanan web lebih tinggi dan user interface dengan prinsip functional programming menjadi komplit. Tujuan khusus penelitian antara lain untuk merancang e-kuisioner dan disesuaikan dengan perkembangan e-kuisioner saat ini serta memudahkan Perguruan Tinggi untuk penyebaran kuisioner dalam bentuk daring sesuai kebutuhan yang lebih fleksibel dibandingkan dengan e-kuisioner yang sudah ada serta memberikan referensi bagi penelitian di Indonesia.

\section{METODOLOGI PENELITIAN}

\subsection{Rancangan Penelitian}

Langkah awal yang dilakukan sebelum memulai penelitian adalah mengumpulkan beberapa literatur yang bersumber dari sejumlah data dan informasi yang sesuai dengan referensi penelitian melalui internet, jurnal, buku dan sebagainya. Setelah sumber data dan informasi terkumpul, langkah selanjutnya adalah menjelaskan tujuan aplikasi yang dibuat, dan menentukan metodelogi yang akan digunakan dalam penelitian. Metodelogi yang digunakan dalam penelitian yang akan dilaksanakan adalah metode DSRM (Design Science Research Method). Adapun penjelasan detail untuk tahapan penelitian adalah seperti dijelaskan pada gambar 1 berikut

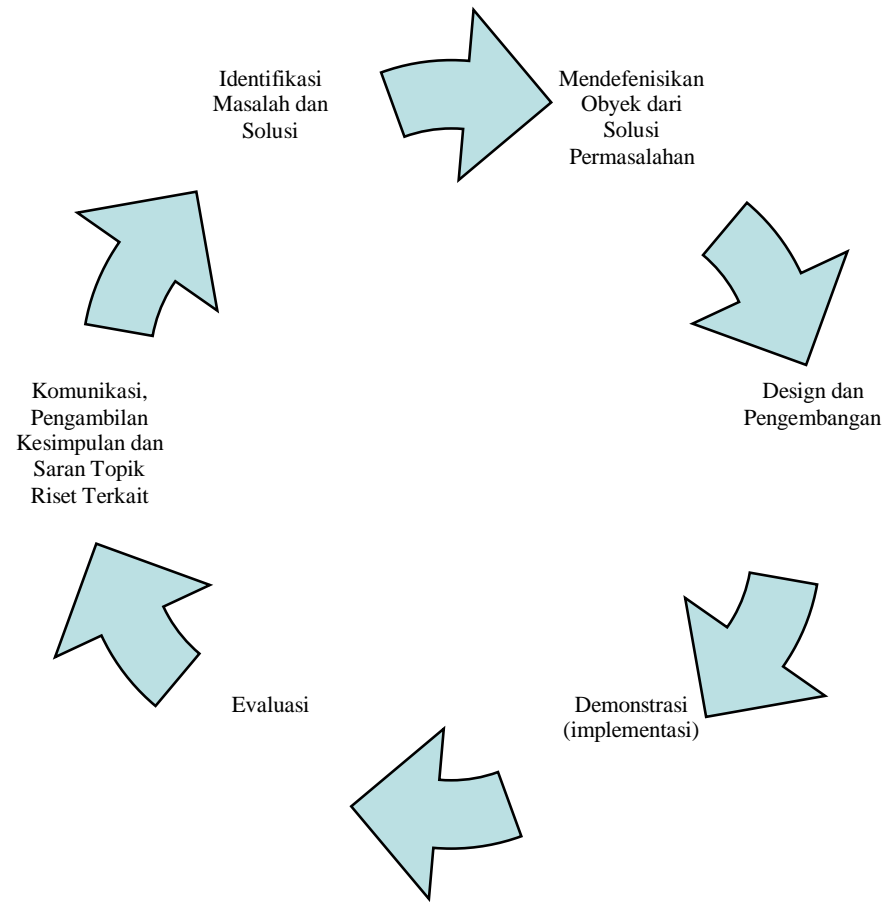

Gambar 1. Kerangka Rancangan Penelitian 
Pada tahap awal dilakukan Identifikasi masalah dan solusi dimana langkah tersebut untuk menemukan masalah dari kondisi atau sistem yang sudah ada, pada konteks ini permasalahan tersebut adalah seputar keterbatasan layanan E-kuisioner. Selanjutnya pada tahap mendefenisikan obyek dari solusi permasalahan dimana langkah berikut adalah menentukan obyek dari solusi masalah dengan cara mengelompokkan permasalahan yang telah diidentifikasi sebelumnya menjadi beberapa kelompok masalah, kemudian memberikan solusi terhadap obyek masalah yang ditemukan. Pada tahap ketiga yaitu design dan pengembangan, dimana perancangan ditujukan untuk membuat pemodelan sementara dari aplikasi baru yang dapat membantu sistem yang sedang berjalan saat ini. Tahap keempat Demonstrasi (implementasi), langkah ini untuk menguji coba sistem dengan menggunakan beberapa tool testing baik pada aplikasi sisi klien maupun aplikasi sisi server untuk memastikan aplikasi sudah berjalan dengan baik. Pada tahap evaluasi, Pada fase testing akan didapati beberapa inputan dari pihak penguji coba (tester). Inputan tersebut akan dievaluasi pada tahap ini untuk kemudian ditentukan bagian mana yang perlu ditingkatkan atau bahkan mungkin perlu dikurangi. Tahap akhir adalah melakukan komunikasi, pengambilan kesimpulan dan saran topik riset terkait dimana pada tahap ini penelitian sudah selesai dilaksanakan dan akan dipaparkan secara umum hasil dari pengembangan E-kuisioner, termasuk kekurangan dan kendala yang dihadapi. Selain itu, bagian ini juga akan memaparkan potensi topik penelitian selanjutnya, termasuk teknologi apa yang dapat dikembangan dengan memanfaatkan purwarupa yang telah diselesaikan pada penelitian ini.

\subsection{Lokasi Penelitian}

Penelitian ini secara pokok akan dilaksanakan pada Laboratorium Rekayasa Perangkat Lunak AMIK Indonesia. Pada laboratorium tersebut terdapat komputer yang dapat digunakan untuk mengembangkan perangkat lunak e-kuisionerpada berbagai sistem operasi khususnya Big Data. Selain itu, penelitian ini juga akan melibatkan mahasiswa dan pengelola perpustakaan di luar lab untuk melakukan uji coba aplikasi yang dibuat.

\subsection{Kerangka Kerja Penelitian}

Kerangka kerja penelitian yang digunakan dalam pengembangan ekuisioner dapat dilihat pada gambar 2 berikut. 


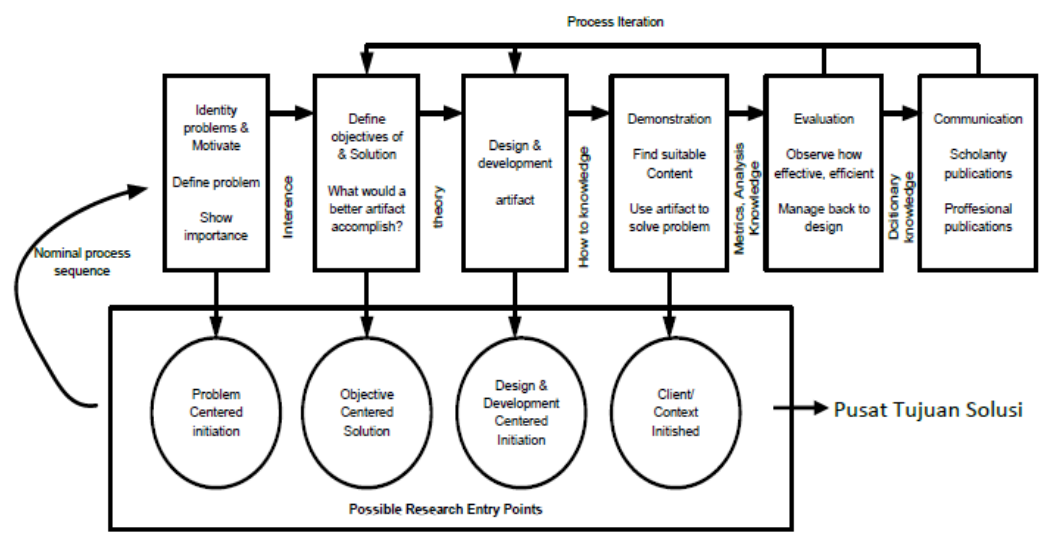

Gambar 2. Kerangka Kerja Penelitian

\section{HASIL DAN PEMBAHASAN}

Hasil dari penelitian ini dalam bentuk sebuah aplikasi e-kuisoner menggunakan CodeIgniter dan React-Js yang berfungsi untuk mendukung kegiatan peneliti melakukan survey kepada responden secara daring. Aplikasi ini mampu membuat sejumlah kuisioner dan hasil dari pengisian kuisioner dapat diekspor ke berbagai bentuk file seperti word dan excell. Adapun kerangka system dan tampilan e-kuisioner dapat dilihat pada gambar 3 sampai dengan 10 .

\subsection{Kerangka Sistem E-Kuisioner}

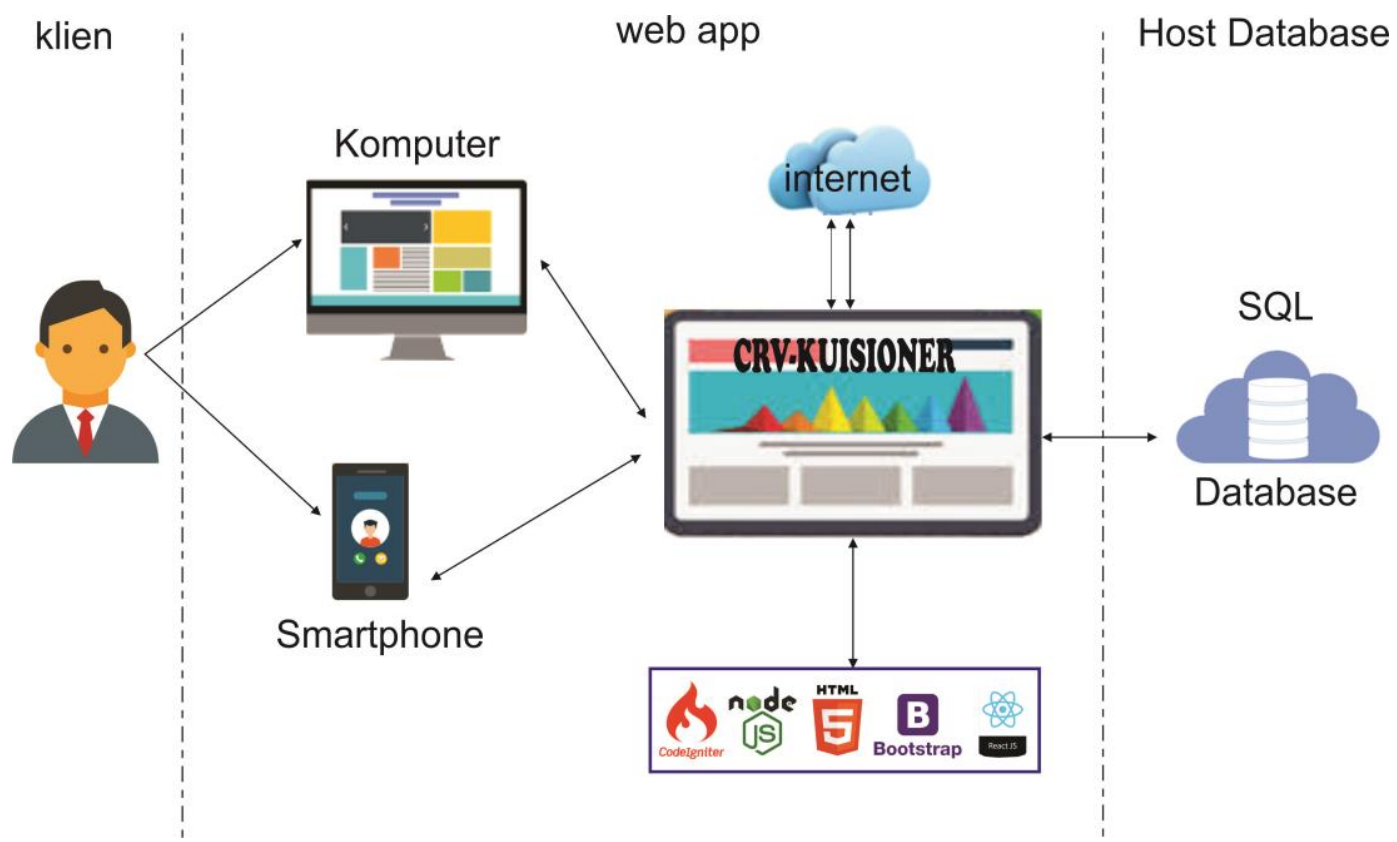

Gambar 3. Kerangka Sistem E-Kuisioner

Berdasarkan gambar 3, pengguna dapat mengakses aplikasi melalui smartphone maupun computer. Setiap klien melakukan penambahan 
kuisoner dan data tersimpan pada database server e-kuisoner. Kuisioner dapat dibagi dan diisi oleh pengguna lain sehingga hasil nanti dapat dilihat oleh pemilik kuisioner (klien). Pada system e-kuisoner ini dibangun dengan menggunakan framework Codelnigter dan React-JS dan beberapa bahasa pendukung seperti HTML dan boostrap. Database yang digunakan adalah SQL yang diletakkan pada server Host (C-Panel).

\subsection{Tampilan Program}

Pada tampilan aplikasi terdiri dari 3 level yaitu; admin, user, dan responden. Berikut akan dijelaskan hasil dari perancangan e-kuisioner yang terdiri dari tampilan utama, login, register, pengguna, section, pertanyaan, responden.

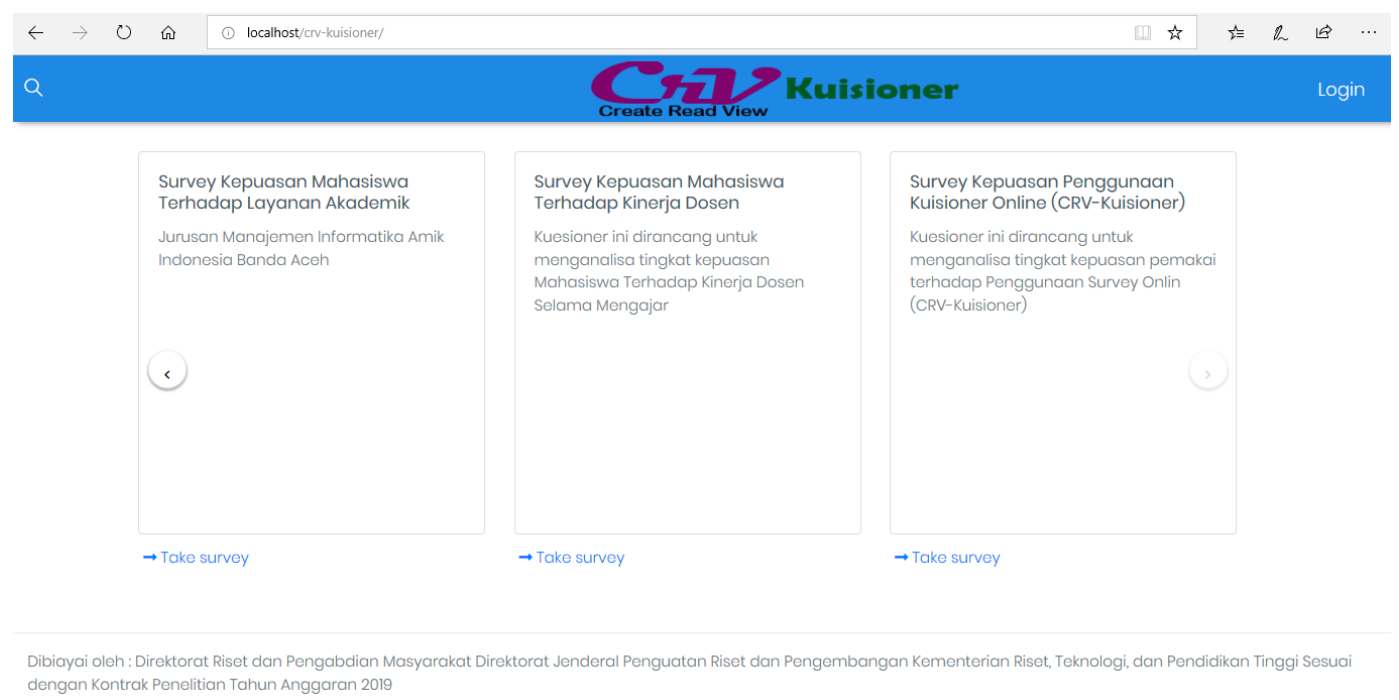

Gambar 4. Tampilan Halaman Utama

Halaman utama ini menampilkan semua survey yang sudah pernah dibuat oleh pengguna pada aplikasi CRV-Kuisoner, dimana nantinya responden dapat menjawab berbagai survey yang tersedia. Akan tetapi bila survey itu ditujukan kepada responden tertentu, pengguna CRV-kuisioner dapat membagikan link kuisionernya kepada respondennya sendiri, misalnya mahasiswa dalam kelas tertentu. Saat memilih kuisioner yang akan diisi, maka akan ditampilkan daftar pertanyaan seperti pada gambar 5 beriku. 
Jurnal Sains Komputer \& Informatika (J-SAKTI)

Volume 3 Nomor 2 September 2019, pp. 337-347

ISSN:2548-9771/EISSN:2549-7200

http://tunasbangsa.ac.id/ejurnal/index.php/jsakti

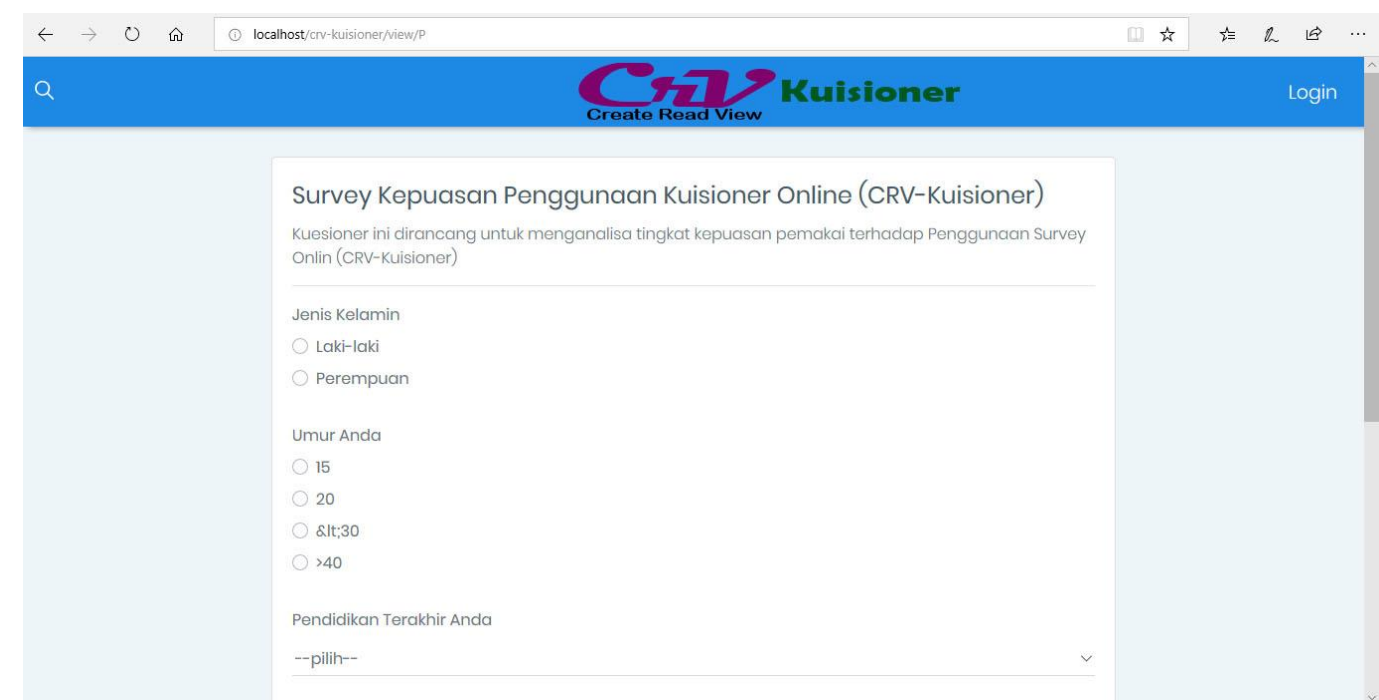

Gambar 5. Tampilan Halaman Daftar Pertanyaan Kuisioner

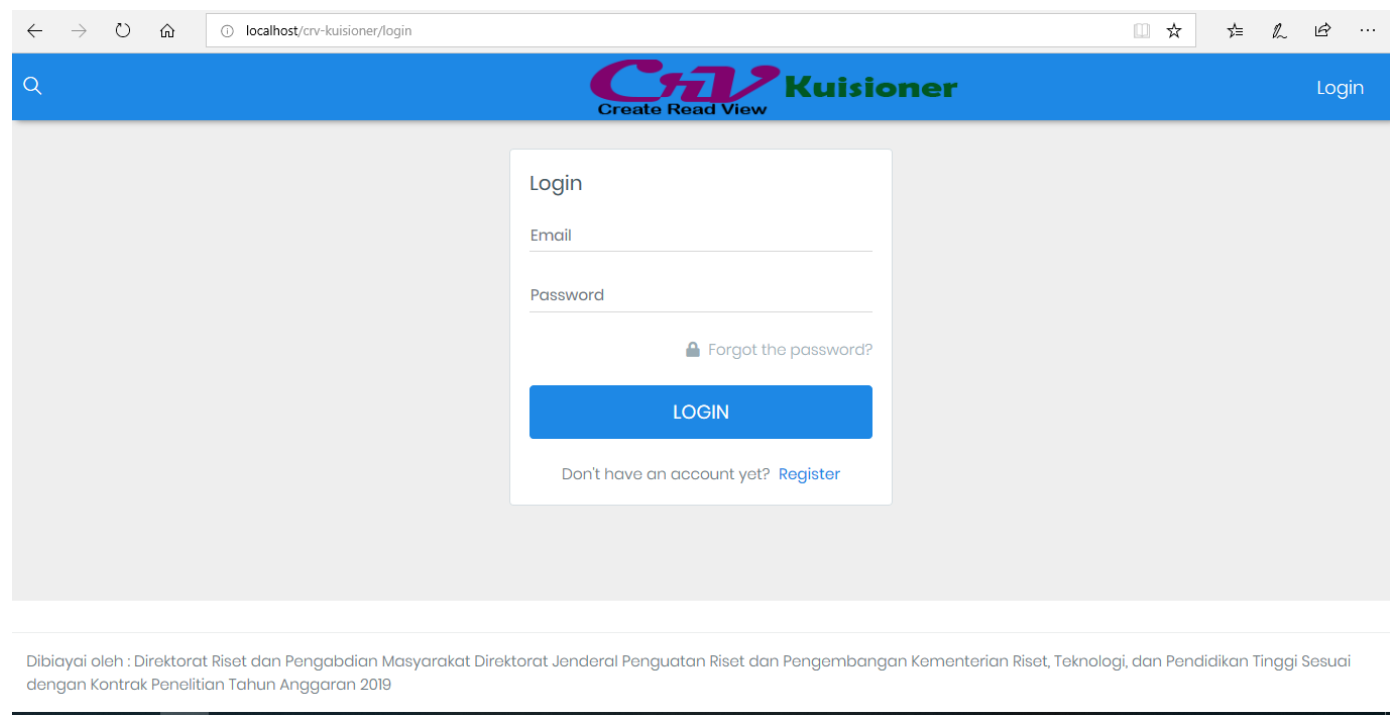

Gambar 6. Tampilan Halaman Login

Halaman login ini digunakan untuk pengguna yang ingin menggunakan CRVKuisioner dalam rangka untuk membuat kuisioner. Untuk membuat kuisioner, langkah awal yang harus dilakukan adalah register seperti pada gambar 7 dan kemudian pengguna baru dapat melakukan login untuk dapat membuat kuisioner. 
Jurnal Sains Komputer \& Informatika (J-SAKTI)

Volume 3 Nomor 2 September 2019, pp. 337-347

ISSN:2548-9771/EISSN:2549-7200

http://tunasbangsa.ac.id/ejurnal/index.php/jsakti

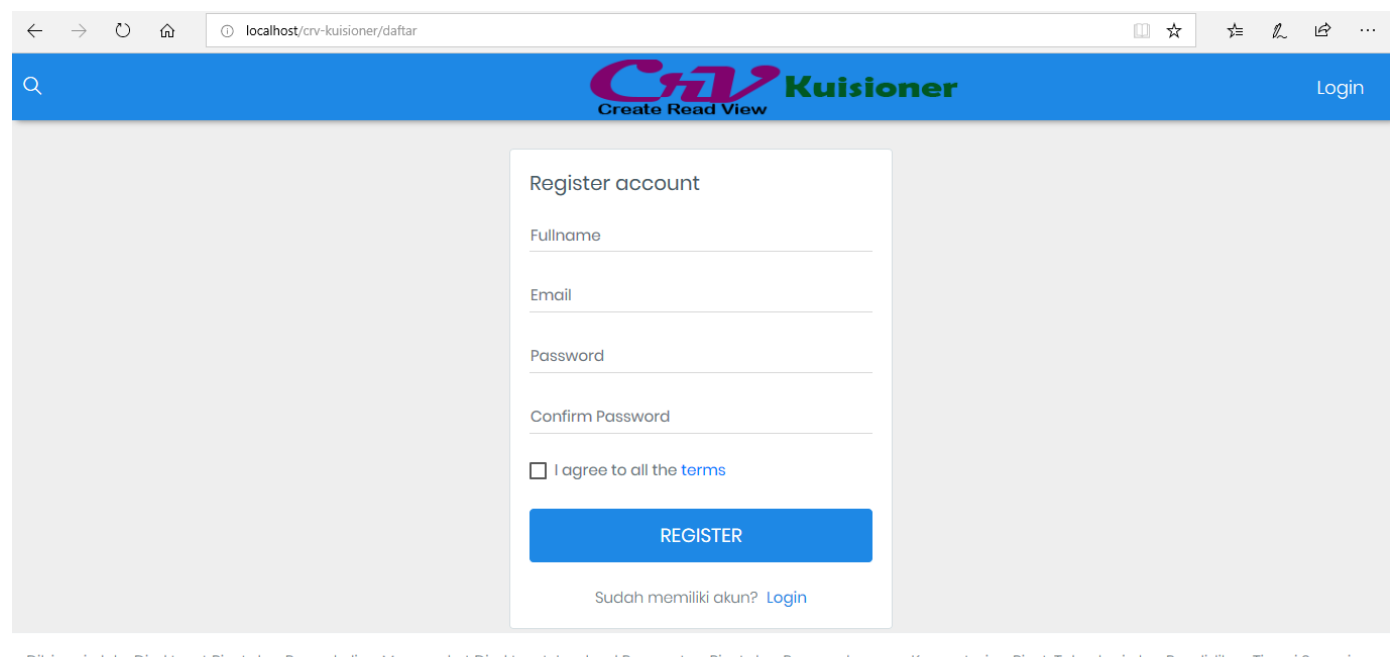

Dibiayai oleh : Direktorat Riset dan Pengabdian Masyarakat Direktorat Jenderal Penguatan Riset dan Pengembangan Kementerian Riset, Teknologi, dan Pendidikan Tinggi Sesua dengan Kontrak Penelition Tahun Anggaran 2019

Gambar 7. Tampilan Halaman Register

Setelah melakukan login maka nantinya akan diarahkan pada halaman utama, halaman ini dapat menampilkan daftar kuisioner yang pernah dibuat sebelumnya pengguna. Pada tampilan ini juga pengguna dapat menambahkan survey baru dengan cara mengklik tombol tambah yang ada pada bagian atas, juga dapat dilakukan pengeditan atau penambahan pertanyaan pada kuisioner yang telah dibuat sebelumnya, serta terdapat layanan untuk membagikan link survey yang dibuat kepada responden tertentu dengan cara klik share dan dapat dilakukan pilihan share ke layanan facebook, Whatsapp maupun share melalui link.

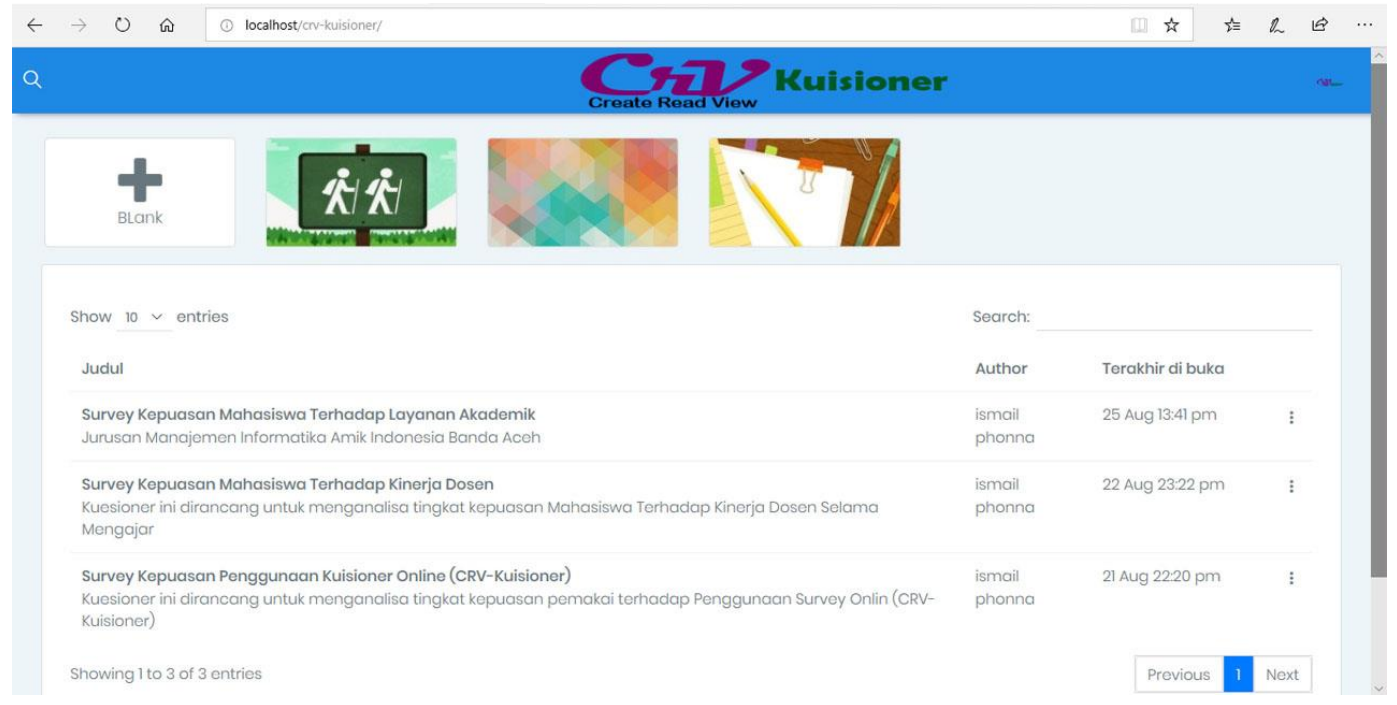

Gambar 8. Tampilan Halaman Utama 
Pada gambar 9, pengisian kuisioner dapat diisi dengan judul survey serta berbagai pertanyaan kuisioner, setiap pengisian pertanyaan kuisioner dapat menggunakan jenis multimedia seperti video, gambar, animasi dan sebagainya. Untuk setiap jawaban pertanyaan kuisioner juga dapat diinput dengan jenis multimedia lainnya.

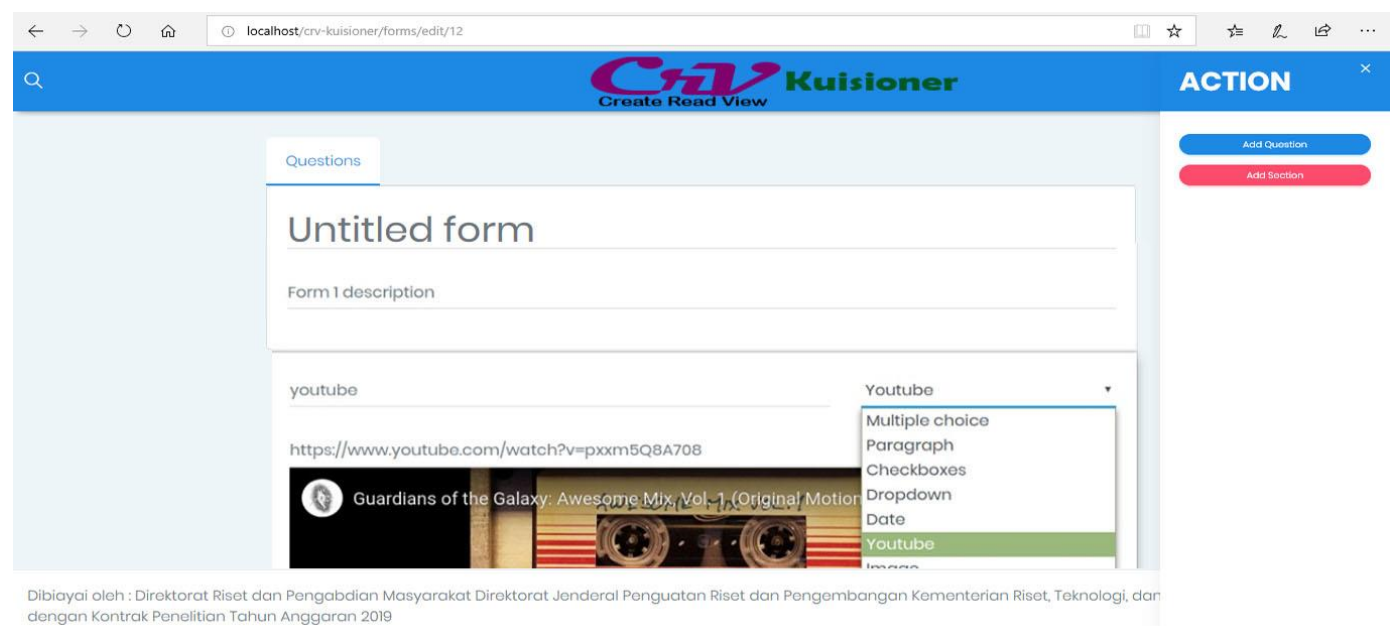

Gambar 9. Input Pertanyaan dalam kuisioner

Pada gambar 10, Halaman ini menampilkan sesi hasil kuisioner serta terdapat informasi terkait pertanyaan dan respon dari pengisi kuisioner baik yang telah menjawab maupun tidak menjawab.

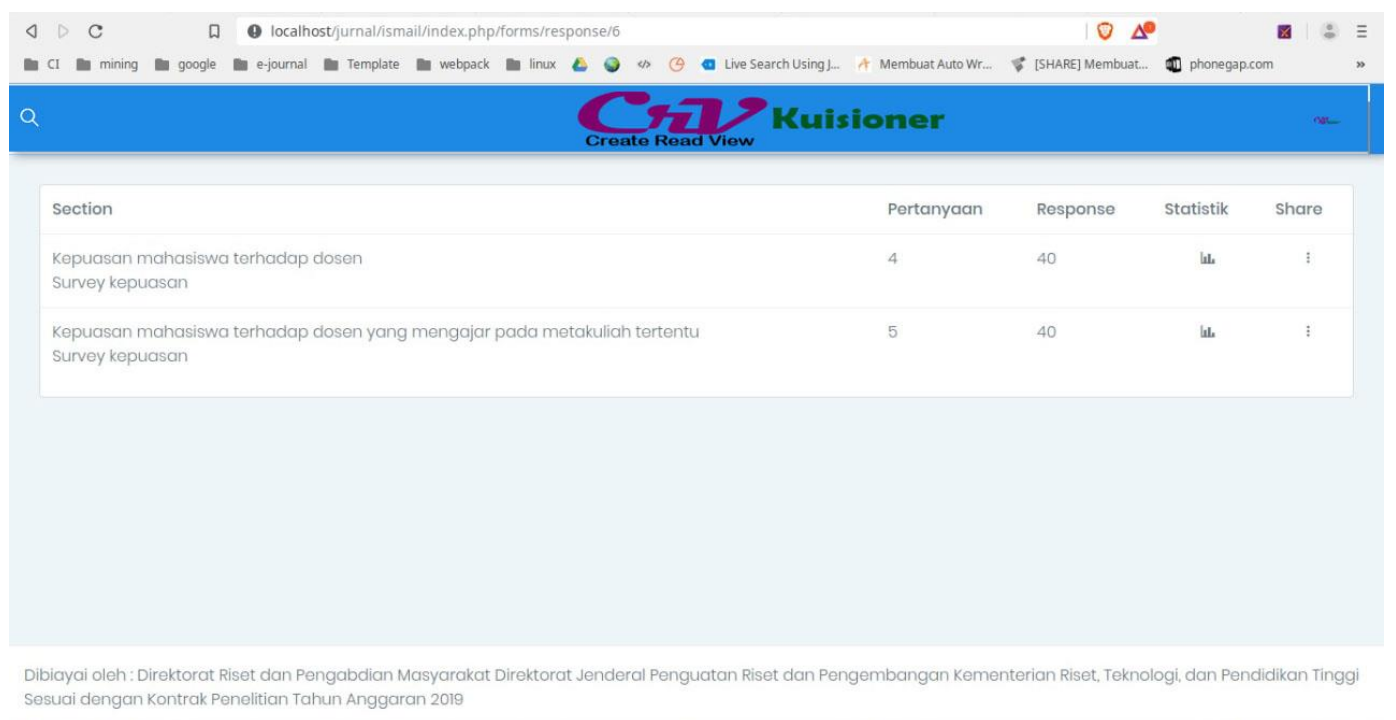

Gambar 10. Tampilan Halaman Section

Pada gambar 11, tampilan grafik merupakan tampilan hasil jawaban yang dijawab oleh setiap responden, dimana setiap jawaban dari responden akan ditampilkan datanya dalam bentuk grafik, dengan jawaban paling banyak 
akan menampilkan grafik yang paling tinggi begitu juga dengan jumlah jawaban yang paling sedikit maka grafiknya akan rendah. Setiap dari hasil penggunaan kuisioner dapat diekspor pada media file word, excell maupun pdf yang dapat digunakan sebagai rekapan kuisioner.

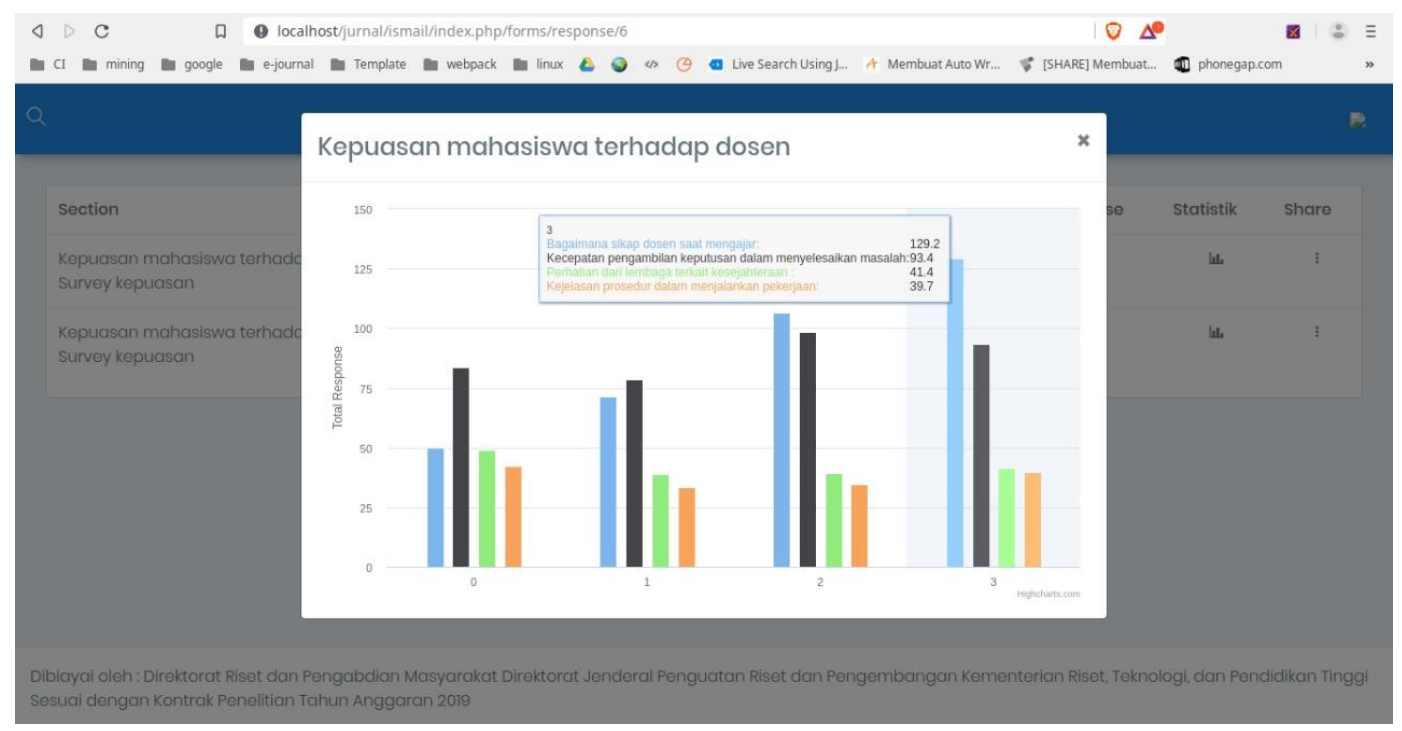

Gambar 11. Tampilan Grafik Hasil Kuisioner

\section{SIMPULAN}

Penelitian ini menghasilkan sebuah rancangan e-kuisioner yang dapat digunakan sebagai alternatif dengan tetap mengutamakan tampilan bagi end user dengan mengadopsi layanan google form tetapi memiliki fitur dengan dapat menambah pertanyaan dalam bentuk multimedia dan juga dapat menyebarkan informasi hasil survei dengan konsep sharing dataset ke berbagai sumber digital online dengan penggunaan framework Codelnigter dan React-Js dapat meningkatkan tampilan yang efektif dengan tetap mengutamakan keamanan sistem. Diharapkan dengan adanya e-kuisioner dapat meningkatkan penyebaran data penelitian dalam bentuk dataset secara elektronik serta sepenuhnya dapat digunakan sebagai referensi bagi peneliti-peneliti di Indonesia khususnya AMIK Indonesia.

\section{UCAPAN TERIMA KASIH}

Ucapan terima kasih sebesar-besarnya kepada Ditjen Penguatan Riset dan Pengembangan Kementerian Riset, Teknologi, dan Pendidikan Tinggi sebagai penyandang dana penelitian ini pada skema Penelitian Dosen Pemula (PDP) Tahun 2019, dan tak lupa pula kepada Lembaga Penelitian dan Pengabdian kepada Masyarakat (LPPM) AMIK Indonesia yang telah memberikan dukungan moril sehingga penelitian ini dapat terlaksana sesuai dengan harapan. Terima kasih juga kepada Tim Pakar dan Dosen AMIK Indonesia yang memberikan saran agar hasil penelitian ini dapat dikembangkan sebagai media solutif dan inovatif. 


\section{DAFTAR PUSTAKA}

[1] Muslihudin, M. and Arumita, A.W., 2016. Pembuatan Model Penilaian Proses Belajar Mengajar Perguruan Tinggi Menggunakan Fuzzy Simple Additive Weighting (SAW)(Sudi: Stmik Pringsewu). SEMNASTEKNOMEDIA ONLINE, 4(1), pp.4-11.

[2] Magoutas, B., Schmidt, K.U., Mentzas, G. and Stojanovic, L., 2010. An adaptive equestionnaire for measuring user perceived portal quality. International Journal of Human-Computer Studies, 68(10), pp.729-745.

[3] Waclawski, E., 2012. How I use it: Survey monkey. Occupational Medicine, 62(6), pp.477-477.

[4] TypeForm. 2018. What's Typeform?. URL : https://www.typeform.com/help/welcome/. Diakses pada tanggal 18 Agustus 2018

[5] Idcloudhost. 2018. Mengenal Google Form untuk Kebutuhan Survey Anda. URL : https://idcloudhost.com/mengenal-google-form-untuk-kebutuhansurvey-anda/. Diakses tanggal 18 Agustus 2018

[6] Zoho. 2015. Zoho Launches Mobile-Ready Survey Tool To Extend Online Business Platform". TechCrunch. July 1, 2013. Retrieved February 4, 2015.

[7] Survey Gizmo. 2018. About SurveyGizmo. URL https://www.surveygizmo.com/company/about/. Diakses tanggal 18 Agustus 2018.

[8] Dhanavandan, S. 2016. Online Tools for Research and Data Collection: An Overview. 1st International Conference on Library and Information Management (ICLIM - 2016), 21st - 22nd October 2016, Department of Library and Information Science, Faculty of Social Sciences, University of Kelaniya, Sri Lanka. p 21.

[9] Mane, M.B. and Kumbhar, R., 2015. Online Tools for Researchers: An Effective Way to Enhance the Quality of Research. International Research: Journal of Library and Information Science, 5(4).

[10] Pasek, J. and Krosnick, J.A., 2010. Optimizing Survey Questionnaire Design in Political Science. In The Oxford handbook of American elections and political behavior.

[11] Sidik, B., 2018. FRAMEWORK CODEIGNITER: Menggunakan Framework Codeigniter 2. X untuk Memudahkan Pengembangan Pemrograman Aplikasi Web dengan PHP 5.

[12] Wali, M. and Ahmad, L., 2018. Perancangan Access Open Journal System (AOJS) dengan menggunakan Framework Codeigniter dan ReactJs. Jurnal JTIK (Jurnal Teknologi Informasi dan Komunikasi), 2(1), pp.48-56. 